\section{Euromonitor data on the illicit trade in cigarettes}

Euromonitor International is a wellknown proprietary data source whose data regarding the global tobacco control community are available for purchase. Euromonitor presents country level data on most high-income countries, and many low-income and middle-income countries on tobacco production, consumption, trade and illicit trade as well as disaggregated data including prices and taxes and narratives on market conditions and tobacco control policy. Although mostly directed at the tobacco industry and allied users (ie, equity analysts), these data are also used by tobacco control researchers and advocates. Data are available from annual reports and from an online database, which are simultaneously updated. The authors subscribe to the data and use Euromonitor as a data source.

The illegal nature of illicit trade makes it intrinsically difficult to measure accurately. We have examined data on trends in illicit trade for specific countries published by Euromonitor from 1997 to 2012 and found striking inconsistencies between country-specific estimates for the same years published in different editions of the report. For example, figure 1 shows the percentage of the total cigarette market (ie, legal and illicit) that are illicit in South Africa published in 2002, 2005, 2007, 2011 and $2012^{1-5}$ (we use the online database for the 2011 and 2012 editions and hard copy reports for older editions since the online database does not store all past editions).

The 2002 data show that the illicit market grew from $12.1 \%$ in 1997 , peaking at 29.9\% in 1999 and declining to $27.1 \%$ in 2001 . Estimates in the 2005 report were markedly lower; for the two overlapping years, 2000 and 2001, the estimates were reduced from $28.4 \%$ and $27.1 \%$ to $1.9 \%$ and $2.2 \%$, respectively. The 2005 report showed a consistently increasing trend in the illicit market through 2005, when it was estimated at $5.3 \%$. While the 2007 report also showed increasing trends, the illicit market estimates were 2-3 times higher than estimates in the previous report. The Euromonitor data published in 2011 were similar to the 2007 data for the time periods that overlapped, with a steep increase from 2006 to 2010. In the most recent (2012) report, the estimate starts at a similar point in 1997 but increases at a slower pace than the 2007 and 2011 estimates.

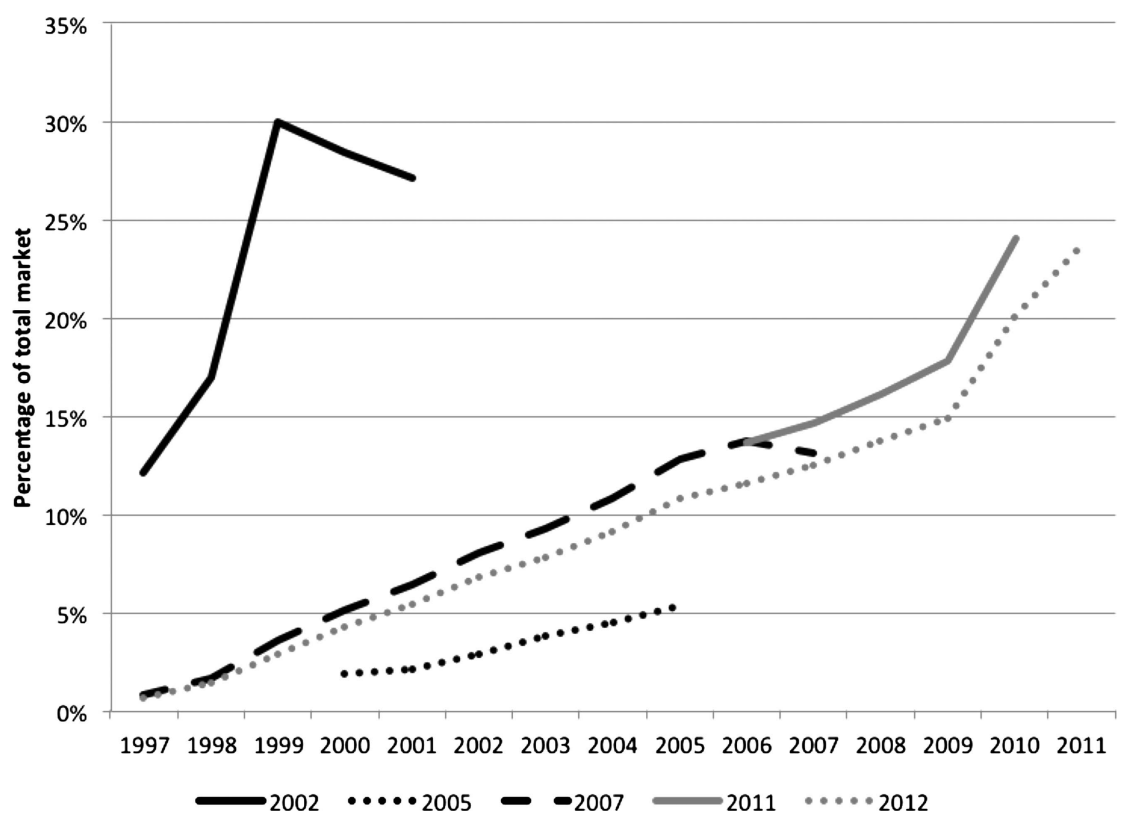

Figure 1 Euromonitor estimates of illicit trade in South Africa. Source: Euromonitor International. ${ }^{1-5}$

Another country of concern is Mexico. Data published in the 2011 report show the illicit market increasing slowly from $3.5 \%$ in 1997 to $6.1 \%$ in $2010^{4}$ (figure 2). The 2012 report shows the illicit market starting at 9.1\% in 1997 (nearly three times the magnitude of the previous estimate) and increasing to $21.8 \%$ of the total market in 2011. ${ }^{5}$

The large discrepancies in annual illicit trade estimates for South Africa and Mexico published in successive editions of the Euromonitor reports are disturbing. Although the authors did not conduct a

comprehensive review of all countries, similar inconsistencies are found with regard to other countries in the Euromonitor data, including Bulgaria, Guatemala and the United Arab Emirates. Euromonitor's tendency to exaggerate illicit trade estimates in Bulgaria has been observed by at least one study. ${ }^{6}$ Unfortunately, independent or official estimates of illicit trade are not available for most countries for comparison and no known official estimates are available for Mexico or South Africa. One independent estimate of illicit trade in South Africa confirms an

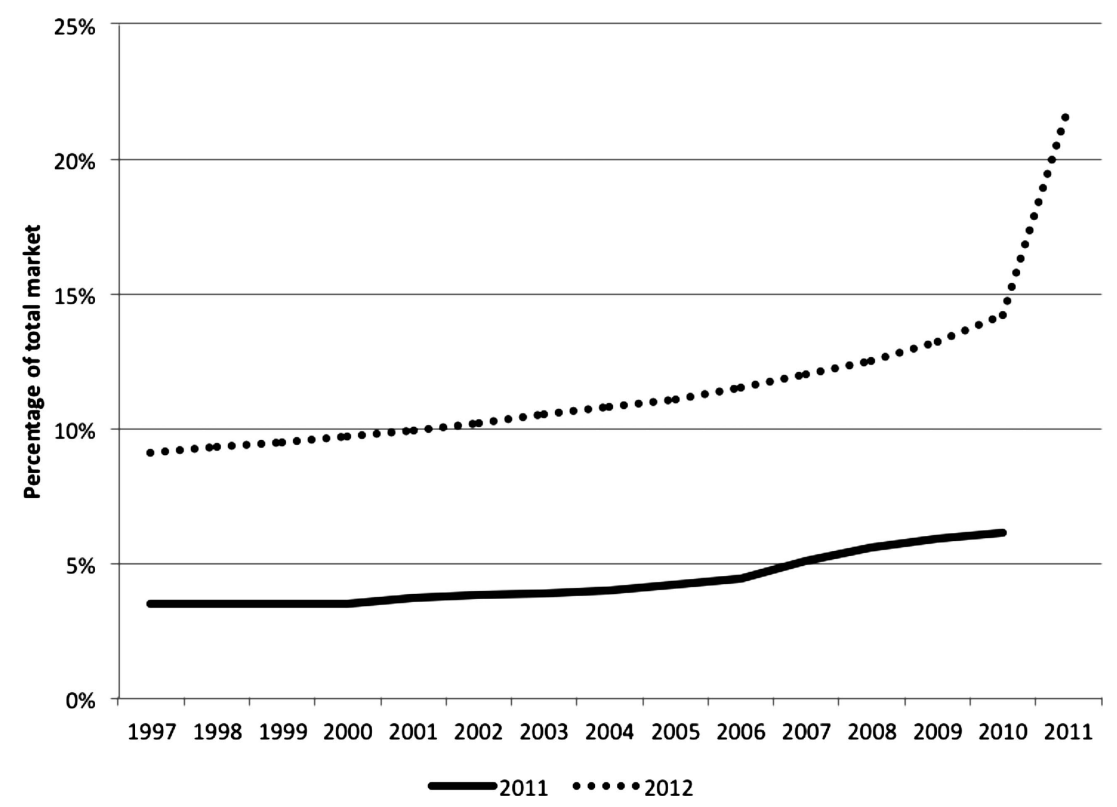

Figure 2 Euromonitor estimates of illicit trade in Mexico. Source: Euromonitor International. ${ }^{45}$ 
upward trend but the increases are significantly lower than the Euromonitor estimates suggest. ${ }^{7}$

Euromonitor states the source of its illicit trade estimates as "official statistics, trade associations, trade press, trade interviews, [and] Euromonitor International estimates". 3 However, the methodology and sources used by Euromonitor are not well-documented, and the discrepancies across editions call into serious question the sources of data and methodology used to derive them.

Euromonitor's reliance on tobacco industry intelligence and an opaque modelling process may lead to biased estimates, especially if information provided by industry sources is influenced by their common narrative that increases in excise taxes cause increases in illicit trade. ${ }^{67} \mathrm{We}$ recommend that investigators exercise increased caution in using Euromonitor data for studies on illicit trade and that new well-documented and verifiable methods are developed to monitor illicit trade that are not dependent on industry data.

\section{What this paper adds}

- Illicit trade estimates published by Euromonitor are regularly used as a data source by the tobacco control community.

- This paper shows that the reliability of these data is questionable and that users should be aware of these concerns.
Evan Blecher, ${ }^{1}$ Alex Liber, ${ }^{1}$ Hana Ross, ${ }^{1}$ Johanna Birckmayer ${ }^{2}$

${ }^{1}$ International Tobacco Control Research Program, American Cancer Society, Atlanta, Georgia, USA

${ }^{2}$ International Research, Campaign for Tobacco Free Kids, Washington, District of Columbia, USA

Correspondence to Dr Evan Blecher, International Tobacco Control Research Program, American Cancer Society, 250 Williams Street NW, Atlanta, GA 30303 , USA; evan.blecher@cancer.org

Contributors All authors contributed to the development and writing of the manuscript.

Competing interests None.

Provenance and peer review Not commissioned; externally peer reviewed.

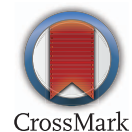

To cite Blecher E, Liber A, Ross $\mathrm{H}$, et al. Tob Control 2015;24:100-101.

Accepted 22 May 2013

Published Online First 21 June 2013

Tob Control 2015;24:100-101.

doi:10.1136/tobaccocontrol-2013-051034

\section{REFERENCES}

1 Euromonitor International 2002. As Published In: International Tobacco Growers Association. Tobacco Courier. International Tobacco Growers Association. 2005.

2 Euromonitor International. Country sector briefing. Euromonitor International. 2005.

3 Euromonitor International. The world market for tobacco. Euromonitor International. 2007.

4 Euromonitor International. Illicit trade penetration statistics. Passport Database. Euromonitor International. 2011.

5 Euromonitor International. Illicit trade penetration statistics. Passport Database. Euromonitor International. 2012.

6 Skafida V, Silver KE, Rechel BP, et al. Change in tobacco excise policy in Bulgaria: the role of tobacco industry lobbying and smuggling. Tob Control 2014;23:e75-84.
7 Blecher EH. A mountain or a molehill: is the illicit trade in cigarettes undermining tobacco control policy in South Africa? Trends Organ Crime 2010;13:299-315. 